OPEN ACCESS

International Journal of Management \& Entrepreneurship Research

P-ISSN: 2664-3588, E-ISSN:2664-3596

Volume 2, Issue 5, P.No. 401-415, October, 2020

Fair East Publishers

Journal Homepage: www.fepbl.com/index.php/ijmer

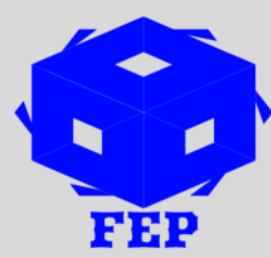

\title{
THE ROLE OF ETHICAL LEADERSHIP IN PROMOTING EMPLOYEE INNOVATIVE WORK BEHAVIOR MEDIATED BY THE PERCEIVED MEANINGFUL WORK AMONG THE ICT SECTOR STAFF IN OMAN
}

\author{
Dr. Muhammad Tahir ${ }^{1}$ \\ ${ }^{1}$ Lecturer (HR), Business Administration Department, \\ University of Technology and Applied Science, \\ Nizwa, Sultanate of Oman
}

Corresponding Author: Dr. Muhammad Tahir

Corresponding Author Email: tahirkhanzaee@gmail.com

Article Received: 05-08-20 Accepted: 01-10-20

Published: $15-10-20$

Licensing Details: Author retains the right of this article. The article is distributed under the terms of the Creative Commons Attribution-NonCommercial 4.0 License (http://www.creativecommons.org/licences/by-nc/4.0/) which permits non-commercial use, reproduction and distribution of the work without further permission provided the original work is attributed as specified on the Journal open access page.

\section{ABSTRACT}

The ICT sector in Oman has a lot of potentials to grow and contribute to the employment creation and diversification of the economy of the country. The sector also faces global international competition and requires to give greater attention to the creative potential of its staff to compete. In the present study, we investigated how ethical leadership can influence employee innovative work behavior with the mediating role of perceived meaningful work. By using the survey method as a primary method of data collection, we generated a useable sample of 121 participants belonged to the ten selected ICT firms. We utilized the SmartPLS version 3 for data analysis. The analysis included an assessment of the measurement model for testing the reliability, convergent validity, and discriminant validity of the constructs for which we found satisfactory results. The second stage of analysis included an assessment of the structural model for hypothesis testing. We found that ethical leadership has positive and significant effects on employee innovative work behavior $(\beta=1.77, \mathrm{P}<.05)$; and perceived meaningful work $(\beta=.815, \mathrm{P}<.05)$. We did not find significant effects of perceived meaningful work on employee innovative work behavior $(\beta=-.077, \mathrm{P}>.05)$. The analysis of indirect effects for testing the mediation hypothesis shows that perceived meaningful work does not work as a mediator between the relationship of ethical leadership and employee innovative work behavior $(\beta=-.634, P>.05)$. Our findings imply that ICT firms should develop ethical 
leadership behavior among the supervisory staff, line managers, and team leaders to facilitate favorable employee outcomes in this particular context.

Keywords: Ethical Leadership, Innovative Work Behavior, Creativity, Meaningful Work, ICT, Oman

\section{INTRODUCTION}

Oman is an important strategic country in the Gulf region and is part of the Gulf Cooperation Council (GCC). Oman Vision 2040 outlines the country's future vision for the next 20 years' time period. The key themes in the Oman Vision 2040 are a society for creative individuals, a competitive economy, and responsible apparatus. Important pillars of the vision 2040 are youth, entrepreneurship, and growth of the knowledge-based sector. In this context, the government in Oman is focusing on developing knowledge-based firms such as communication, software development, and IT is collectively known as ICT. The ICT industry is receiving a lot of attention from the government as according to OmanObserver (2019, authorities in Oman assembled a portfolio of strategic projects and initiatives exceeding RO 100 million to boost the ICT sector in the sultanate. These initiatives are expected to attract further investment and create more than 2000 direct jobs and several indirect job opportunities. The ICT sector contribution to the Oman economy is about $2.1 \%$ in the country's GDP which government envisions to increase in upcoming years. The sector also faces higher competition from the ICT sector of other countries such as neighboring UAE as well as India and Pakistan. For growth in the ICT sector, there requires greater attention to the development of staff potential and staff creativity in this particular context is one such factor which can facilitate the ICT firms to become globally competitive (Huang, Geng, \& Wang, 2017). Despite the sector importance and associated importance of Human resource issues, there is a shortage of empirical investigations related to this sector. Thus, there is a valid literature gap which this study intends to fill by testing the influence of ethical leadership on employee innovative work behavior.

\section{Research Questions}

The study is based on the following research questions

Q1: What are the effects of ethical leadership on employee innovative work behavior?

Q2: What are the effects of employee perceived meaningful work on employee innovative work behavior?

Q3: What are the effects of ethical leadership on employees' perceived meaningful work?

Q4: Is employee perceived meaningful work plays the mediating role between ethical leadership and employee innovative work behavior?

\section{Objectives of the Study}

The objectives of the study are as follows;

- To measure the effects of ethical leadership on employee innovative work behavior.

- To measure the effects of employee perceived meaningful work on employee innovative work behavior.

- To measure the effects of ethical leadership on employee perceived meaningful work.

- To test the mediating role of perceived meaningful work between the relationship of ethical leadership and employee innovative work behavior. 


\section{Significance of the Study}

The study makes at least four important contributions. The first contribution of the study is we filled the literature gap by employee innovative work behavior and ethical leadership as its predictor in this particular context of the ICT sector in Oman; a topic that is less investigated in the existing literature. The second contribution of the study is that we added the perceived meaningful work as a mediator and empirically tested to better understand the nature of relationship between innovative work behavior and ethical leadership as its predictor. The third contribution of the study is that we investigated the innovative work behavior and ethical concepts in a Middle Eastern country context. It is a contribution since such concepts are context-dependent. The fourth contribution of the study is that we enriched the componential theory of creativity and further strengthen the idea that employee creativity at the workplace is influenced by environmental factors such as leadership which need managerial attention.

\section{LITERATURE REVIEW}

\section{Ethical Leadership}

The initial literature on leadership attempted to identify the common traits among successful leaders to differentiate successful leaders' traits from those of the failed leaders (Avolio, 1999). Thus, earlier leadership literature focused on the personality traits and characters of effective leaders. Bass (1990) thus defines leadership as a person who is restructuring the problem, offering solutions, establishing priorities, and initiating developmental operations. In contrast to this, the existing definitions of leadership mostly focus on leader-member exchange or interaction (Yukl, 2017). Literature also identified a range of leadership styles out of which classification such as democratic versus autocratic, and transactional versus transformational received the greatest attention. However, now the attention is shifted to the new concept of leadership such as ethical leadership, servant leadership, and authentic leadership. Kalshoven, Den Hartog, \& De Hoogh (2011) for example stated that there is a greater emphasis on ethical leadership especially in the late 1990s and first decade of the $21^{\text {st }}$ century. This increased attention to ethical leadership can also be attributed to several corporate scandals, the global financial crisis, and the recent Coronavirus crisis, which highlighted the need for leaders to be ethical. For this study, we define ethical leadership as an individual leader who demonstrates normatively appropriate conduct through personal actions and interpersonal relationships, and the promotion of such conduct to followers through twoway communication, reinforcement, and decision making (Brown \& Treviño, 2006). The common qualities of ethical leadership are fairness, honesty, care, and credibility (Jordan, Brown, Treviño, \& Frinkelstein, 2013). We can identify that the definition of ethical leadership focuses on positive moral aspects such as care and accountability as well as communication with the followers. The importance of ethical leadership is obvious since, without ethical leadership, ethical principles cannot be communicated to the followers who may copy the unethical practices of unethical role models (Pulapa, 2020). Another importance of ethical leadership is that it provides a psychologically safe work environment to the followers which foster greater performance among the followers (Browne, 2020). Having ethical leadership means organizational members can take their inspiration from such leadership who serve as role models (Walumbwa, Luthans, Avey, \& Okey, 2011). In terms of leadership styles, it can be seen that democratic leaders are more ethical compare to autocratic. Furthermore, transformational leadership style suits developing the ethical values 
among followers using positive mechanism compare to the transactional leadership style who may use the less effective method of reward and punishment for developing such ethical values among the followers (Browne, 2020; Schaubroeck, Hannah, Avolio, Kozlowski, Lord, Treviño, \& Peng, 2012). Overall, we can say that ethical leadership is important and plays important role in the current dynamic work environment in which an organization operates.

\section{Innovative Work Behavior}

Creativity refers to the production of novel and useful ideas in any domain, and innovation as the implementation of creativity (Amabile, Conti, Coon, Lazenby, \& Herron, 1996). The distinction between both concept is that creativity is about the development of new ideas and the innovation is about the implementation of the creative ideas into action. In organizational research, often creativity is difficult to measure directly, therefore, most researchers use innovative work behavior or some other suitable variables for indirectly tapping into the concept of creativity. In the present study, we use the innovative work behavior of staff as an indirect measure of employee creativity. West and Farr (1990) view innovative work behavior as employees behavior associated with generating, introducing, and applying some new process, product, procedure, or idea for the purpose of significant benefit or improvement. In another words, employee's innovative work behavior includes introduction of some useful new ideas, process, or procedures along with its implementation (De Jong \& Den Hartog, 2010). Employee innovative work behavior is important since it is a requirement to meet the challenges of the current dynamic market and also serve as a source of competitive advantage (Abstein \& Spieth, 2014). Ethical leadership can play important role in shaping employee innovative work behavior since ethical leadership can create a supportive and safe climate that is necessary for creativity to occur (Duan, Liu, \& Che, 2018). Thus, an organization needs to have a supporting culture for promoting innovative work behavior.

Employee creativity and innovative work behavior are predicted by different factors that are established in the literature. Earlier studies focused on employee-related factors such as personality traits and internal motivation for employees to be engaged in innovative work behavior (e.g. Oldham \& Cummings, 1996). However, the second school of thought is that employee innovative work behavior is also influenced by work environment factors such as leadership, organizational culture, and safety climate (Amabile et al., 1996). Examples of other work environmental-related factors include but are not limited to extent of teamwork, organizational support, resource availability, autonomy, and encouragement from the organization (Moghimi \& Subramaniam, 2013). It is reasonable to assume that most of the environmental factors are also partially influenced by leadership so leadership style plays important role in shaping innovative work behavior among employees. In previous studies, the leadership styles such as transformational-transactional, and autocratic-democratic influencing on employee innovative work behavior or creativity is established (e.g. Ma \& Jiang, 2018; Radwan, 2020). However, fewer studies are testing the influence of ethical leadership style on employee innovative work behavior. This is the literature gap we intend to fill in the present study.

The Relationship between Ethical Leadership Style and Employee Innovative Work Behavior

Generally, leadership style can make a significant influence on employee work-related behavior (Radwan, 2020; Tsai \& Tseng, 2010). Similarly, ethical leadership can also 
influence an employee's work-related behaviors (Duan et al., 2018). The relationship between both constructs can be based on the dual mechanism of cognition and motivation. The cognitive part covers the greater attention paid to the work by the followers under the ethical leadership style; while, the motivational part covers the motivation to engage in positive behavior due to the positive feelings such as dignity, pride, and respect which leads to the higher self-efficacy and morale among workers (Amabile et al., 1996). Empirical studies such as the study by Duan et al., (2018) in the Chinese context established a positive influence of ethical leadership on employee creativity while partially mediated by psychological empowerment and willingness. Another study by Feng, Zhang, Liu, Zhang, and Han (2018) indicated curvilinear relationship between ethical leadership and employee creativity while intrinsic motivation partially mediates this curvilinear relationship. A study by Shafique, Ahmad, and Kalyar (2019) indicated a positive significant influence of ethical leadership on individual and organizational level creativity. Furthermore, knowledge sharing and psychological empowerment play a mediating role in this relationship. A study by Javed, Khan, Bashir, and Arjoon (2017) also showed that ethical leadership influences employee creativity while psychological empowerment mediates this relationship. A study by Zahra, Ahmad, and Waheed (2017) conducted in the IT sector context showed that ethical leadership influences employee innovative work behavior while self-efficacy mediates this relationship. Besides the above-mentioned empirical studies, we also used the dynamic componential model of creativity and innovation by Amabile and Pratts (2016) which states that employee's innovation is influenced by a desirable work environment. In this context, it means that if there is ethical leadership, it will create a psychologically safe and healthy work environment that is necessary for creativity to flourish. Thus, utilizing the evidence from empirical studies and the dynamic componential model of creativity and innovation, we propose that employee innovative work behavior is predicted by ethical leadership. Our specific hypothesis is as follows;

H1: Perceived ethical leadership has a positive and significant influence on employee innovative work behavior

\section{The Relationship between Meaningful Work and Employee Innovative Work Behavior}

Meaningful work refers to the work that employees believe is significant in that it serves an important purpose (Pratt \& Ashforth, 2003). In other words, meaningfulness is about the extent to which employees believe that their work is significant. The challenging nature of ICT sector firms shows that for employees, meaningful work is important as it creates internal motivation for employees to work and pursue their goals (Martela \& Pessi, 2018; Steger \& Dik, 2010). Another reason for the importance of meaningful work for the ICT sector is that such firms are characterized by higher innovation orientation and come up with associated challenges (Simonton, 1999). Thus, employees who experience meaningful work feel that their work is making a significant contribution to the work, organization, and society at large which encourages greater innovation at the workplace (Grant \& Berry, 2011).

Perceived meaningful work is found to be influencing employee creativity and innovative work behavior (Liden, Wayne, Liao, \& Meuser, 2014; Soane, Shantz, Alfes, Truss, Rees, \& Gatenby, 2013). This is because such employees are intrinsically motivated to work as they find their work significant, valuable, and purposeful (Tu \& Lu, 2013). In other words, employees who find their work meaningful feel that their work is contributing to greater 
benefit for society which increases employees' willingness to make full use of their creative potential (Akgunduz, Alkan, \& Gök, 2018; Pradhan \& Jena, 2019). Therefore, we propose the following hypothesis.

H2: Employee perceived meaningful work has positive and significant effects on employee innovative work behavior

\section{The Relationship between Ethical Leadership Style and Employee Perceived Meaningful Work}

The underlying argument for the employee innovative work behavior predicted by ethical leadership is that such leadership gives close attention to the employees and related issues such as grievance, safety, and development needs. Thus, we expect that ethical leadership significantly influences employee innovative work behavior. Furthermore, empirical studies also show that ethical leadership leads to meaningfulness at work. For instance, Wang and Xu (2019) study indicated that ethical leadership exerts a significant influence on employees' perceived meaningful work. Another study by Mostafa and Abed El-Motalib (2020) showed a positive impact of ethical leadership on employee meaningfulness work among the employees of public sector organizations. Based on the previous studies' findings, we propose the following hypothesis.

H3: Ethical leadership has positive and significant effects on employees' perceived meaningful work.

\section{Mediating Role of Meaningful Work}

Literature shows that different mediators are influencing the employee innovative work behavior and ethical leadership relationship. Examples of such mediator include psychological empowerment and willingness (Duan et al., 2018; Javed et al., 2017); intrinsic motivation (Feng et al., 2018); knowledge sharing (Shafique et al., 2019); and self-efficacy (Zahra et al., 2017). In the present study, we used meaningful work as a mediator since it is not investigated in previous studies with this set of exogenous and endogenous variables. The underlying argument for meaningful work as a mediator is that it is predicted by ethical leadership (Mostafa \& Abed El-Motalib, 2020; Wang \& Xu, 2019) and also found to be influencing employee innovative work behavior (Akgunduz et al., 2018; Pradhan \& Jena, 2019; Tu \& Lu, 2013). Thus, we expect that it may function as a mediator and connecting the two constructs. Therefore, we propose the following hypothesis.

H4: Employees perceived meaningful work significantly mediate the relationship between ethical leadership and employee innovative work behavior.

\section{RESEARCH METHODOLOGY}

\section{Research Design}

The study design is explanatory and cross-sectional. Explanatory design means we attempt to find the effects of one or more variables on the dependent variable which is the innovative work behavior in our study. The cross-sectional design means that data is only collected once from the participants.

\section{Population and Sampling}

The ICT sector in Oman is the prime focus of the study and the sector is the population of the study. We used the sampling approach for data collection. We selected ten ICT firms with a combined staff of about 1500. We used the sample size calculator developed by Bartlett, Kotrlik, and Higging (2001). Based on the .03 margin of error, and 5\% alpha level, our 
required sample size is 110 . In total, we distributed 186 surveys out of which we got a response of 121 so making a response rate of $65 \%$.

\section{Data Collection Instrument}

We collected data through existing measures. The ethical leadership scale is adapted from Brown and Treviño (2006) consist of 10 items. The scale of the Innovative work behavior of employees is adapted from Janssen (2000) and is measured by 9 itemsThe scale for Meaningful work is known as 'Work and Meaning Inventory' is adapted from the Steger, Dik, and Duffy, (2012) and consists of 10 items.

\section{Reliability and Validity}

For measuring the reliability, we used the Cronbach alpha and Composite reliability and the cutoff value we used is above 0.70 . The validity is established by testing the convergent and discriminant validity through CFA conducted through SmartPLS. The details are in the result section.

\section{Data Analysis}

Data once collected is fed into SPSS and screened for any discrepancies. We used SmartPLS for data analysis. The analysis consists of two stages including assessment of the measurement model for validity and reliability purpose, and the assessment of the structural model for testing the hypotheses.

\section{Ethical Issues}

We made sure that ethical issues based on academic norms are followed. For example, we did not force anyone to participate in the study. No participant is given any incentive or deceived to take part in the survey. All collected data is used only for the purpose of the study and participant privacy is ensured.

\begin{tabular}{|c|c|c|c|}
\hline \multicolumn{4}{|c|}{$\begin{array}{l}\text { RESULTS } \\
\text { Demographic Information of the Survey Participants } \\
\text { Table } 1 \\
\text { Demographic Information }\end{array}$} \\
\hline 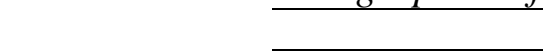 & 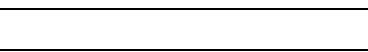 & Frequency & Percentage \\
\hline \multirow{2}{*}{ Gender } & Male & 90 & $74.4 \%$ \\
\hline & Female & 31 & $25.6 \%$ \\
\hline \multirow[t]{4}{*}{ Age } & 18 to 25 Years & 21 & $17.4 \%$ \\
\hline & 25 to 35 Years & 37 & $30.6 \%$ \\
\hline & 35 to 45 Years & 34 & $28.1 \%$ \\
\hline & Above 45 Years & 29 & $24.0 \%$ \\
\hline \multirow[t]{4}{*}{ Role } & Software Developer & 72 & $59.5 \%$ \\
\hline & Network Administrator & 26 & $21.5 \%$ \\
\hline & Database Administrator & 16 & $13.2 \%$ \\
\hline & Others & 7 & $5.8 \%$ \\
\hline \multirow{4}{*}{ Work Experience } & Less than 1 Years & 25 & $20.7 \%$ \\
\hline & 1 to 5 Years & 35 & $28.9 \%$ \\
\hline & 5 to 15 Years & 43 & $35.5 \%$ \\
\hline & Above 15 years & 18 & $14.9 \%$ \\
\hline
\end{tabular}

A total of 121 staff of selected ICT firms participated in the survey out of which 90 were male (74.4\%) and 31 were female $(25.6 \%)$. The age classification of the participant was such that 25 to 35 years was the highest category with 37 participants (30.6\%) followed by 35 to 45 years $(28.1 \%)$. There were 29 participants above 45 years of age $(24 \%)$; followed by 21 participants (17.4\%) falling in the 18 to 25 years category. In terms of job role, 72 belonged to 
the software developer category (59.5\%); 26 were network administrator category $(21.5 \%) ; 16$ were database administrator (13.2\%); and 7 belonged to the other category $(5.8 \%)$. There were 25 participants with less than 1 years' work experience $(20.7 \%)$; 35 had 1 to 5 years work experience (28.9\%); 43 had 5 to 15 years work experience (35.5\%); and 18 had above 15 years work experience (14.9\%).

\section{Assessment of Measurement Model}

For the analytical part, our first step was the assessment of the measurement model which we performed using the Smart PLS software. We analyzed data using the Partial Least Square which is a variance-based structural equation modeling approach (Roldán \& Sánchez-Franco, 2012). We used Smart PLS because of its robustness and incremental character in predicting endogenous variables (Hair, Sarstedt, Ringle, \& Gudergan, 2017; Ringle, Wende, \& Becker, 2015). We used confirmatory factor analysis (CFA) for testing the validity of dimensions and items of the proposed measurement model. The results are presented in the following table.

Table 2

Convergent Validity and Reliability of Variables

\begin{tabular}{|c|c|c|c|c|c|}
\hline Variable/ Construct & Items & $\begin{array}{c}\text { Standardized } \\
\text { Factor } \\
\text { Loadings } \\
\end{array}$ & $\begin{array}{l}\text { Cronbach } \\
\text { Alpha }\end{array}$ & $\begin{array}{l}\text { Composite } \\
\text { Reliability }\end{array}$ & $\begin{array}{c}\text { Average } \\
\text { Variance } \\
\text { Extracted }\end{array}$ \\
\hline \multirow{10}{*}{ Ethical Leadership } & EL1 & .698 & \multirow{10}{*}{.779} & \multirow{10}{*}{.781} & \multirow{10}{*}{.598} \\
\hline & EL2 & .825 & & & \\
\hline & EL3 & .754 & & & \\
\hline & EL4 & .910 & & & \\
\hline & EL5 & .779 & & & \\
\hline & EL6 & .768 & & & \\
\hline & EL7 & .677 & & & \\
\hline & EL8 & .730 & & & \\
\hline & EL9 & .776 & & & \\
\hline & EL10 & .795 & & & \\
\hline \multirow{9}{*}{ Innovative Work Behavior } & IWB1 & .895 & \multirow{9}{*}{.811} & \multirow{9}{*}{.815} & \multirow{9}{*}{.608} \\
\hline & IWB2 & .789 & & & \\
\hline & IWB3 & Deleted & & & \\
\hline & IWB4 & .783 & & & \\
\hline & IWB5 & .800 & & & \\
\hline & IWB6 & .784 & & & \\
\hline & IWB7 & .742 & & & \\
\hline & IWB8 & .728 & & & \\
\hline & IWB9 & .705 & & & \\
\hline \multirow{10}{*}{$\begin{array}{l}\text { Perceived Meaningful } \\
\text { Work }\end{array}$} & M1 & .818 & \multirow{10}{*}{.782} & \multirow{10}{*}{.711} & \multirow{10}{*}{.848} \\
\hline & M2 & .854 & & & \\
\hline & M3 & .804 & & & \\
\hline & M4 & .925 & & & \\
\hline & M5 & .790 & & & \\
\hline & M6 & .853 & & & \\
\hline & M7 & .858 & & & \\
\hline & M8 & .762 & & & \\
\hline & M9 & .816 & & & \\
\hline & M10 & .742 & & & \\
\hline
\end{tabular}

We only deleted one item due to the low factor loading (IWB3). The revised model result that all variables have good internal consistency as Cronbach alpha and Composite Reliability are above 0.70 for all variables. For validity, we analyzed individual factor loadings for all items and found that all values are above 0.60. The Average Variance Extracted is also above 0.50 
so it is an indication of good convergent validity (values suggested by Hair et al., 2017). After the satisfactory results for the convergent validity and reliability, we moved on to test the discriminant validity.

Table 3

\begin{tabular}{lccc} 
Discriminant Validity & & & \\
\hline & 1 & 2 & 3 \\
\hline Ethical Leadership & $\mathbf{. 7 7 3}$ & .434 & .567 \\
Perceived Meaningful Work & .434 & $\mathbf{. 7 8 0}$ & .654 \\
Innovative Work Behavior & .567 & .654 & $\mathbf{. 9 2 0}$ \\
\hline
\end{tabular}

For establishing discriminant validity, we used the Fornell and Larcker (1981) criteria. The values in the diagonal bold are the square root of AVE and other values are inter-variable correlation. The requirement is that the diagonal bold values should be higher than other values in its respective rows and column which are met as can be seen in the table. Thus, we can say that our variables have good discriminant validity. After assessing the measurement model and satisfactory results for the reliability, convergent validity, and discriminant validity, we next assess the structural model for the hypotheses testing.

\section{Assessment of Structural Model}

The criteria used for assessing the structural model include multicollinearity assessment, $\mathrm{t}$ statistics, path coefficients, Predictive relevance of the model $\left(\mathrm{Q}^{2}\right)$, effect size $\left(\mathrm{f}^{2}\right)$, and coefficient of determination $\left(\mathrm{R}^{2}\right)$, For assessing the multicollinearity, we used the VIF or variance inflation factor.

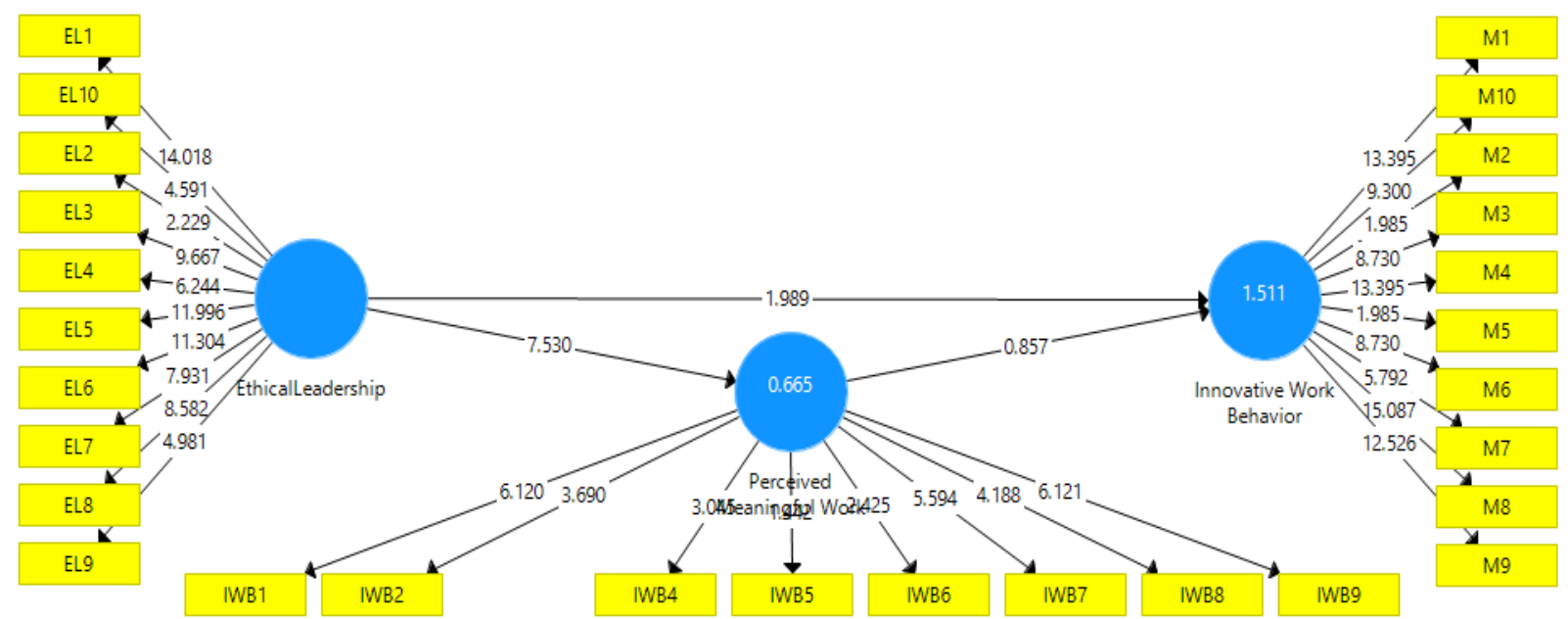

Figure 1: Structural Model with Results

The VIF values for the variables are provided in the following table.

Table 4

Multicollinearity Assessment

\begin{tabular}{lcc}
\hline & $\begin{array}{c}\text { Perceived Meaningful } \\
\text { Work }\end{array}$ & $\begin{array}{c}\text { Employee Innovative } \\
\text { Work Behavior }\end{array}$ \\
\hline Ethical Leadership & 1.433 & 1.546 \\
Perceived Meaningful Work & - & 1.763 \\
Employee Innovative Work Behavior & - & - \\
\hline
\end{tabular}


Our assessment of the VIF shows that all values are less than the threshold values of 5 indicating absence of any serious issue related to multicollinearity in the study dataset. The threshold value of VIF is 5 which is based on the guidelines set by Hair et al., (2017) and Ringle et al., (2015). Next, we used the bootstrapping based on 5000 resamples and $95 \%$ based Bias corrected and Accelerated bootstrap.

Table 5

Hypotheses Testing (Structural Model)

\begin{tabular}{clcccccccc}
\hline H. No. & \multicolumn{1}{c}{ Path } & $\begin{array}{c}\text { Original } \\
\text { Sample } \\
(\mathbf{O})\end{array}$ & $\begin{array}{c}\text { Sample } \\
\text { Mean } \\
(\mathbf{M})\end{array}$ & $\begin{array}{c}\text { Standard } \\
\text { Deviation } \\
(\text { STDEV })\end{array}$ & $\begin{array}{c}\text { T Statistics } \\
(\mid \mathbf{O} / \mathbf{S T D E} \\
\text { V] }]\end{array}$ & R2 & f2 & Q2 & $\begin{array}{c}\text { P- } \\
\text { Values }\end{array}$ \\
\hline H1 & EL $>$ IWB & 1.778 & 2.013 & .894 & 1.989 & & .12 & & .047 \\
H2 & PMW $>$ IWB & -.077 & -1.000 & .908 & .857 & .511 & .05 & .67 & .392 \\
H3 & EL $>$ PMW & .815 & .822 & .108 & 7.530 & .665 & .11 & .78 & .000 \\
\hline
\end{tabular}

Key findings are that ethical leadership has a significant positive effects on employee innovative work behavior $(\beta=1.778, \mathrm{P}<.05)$. The Perceived meaningful work has an insignificant negative effects on employee innovative work behavior $(\beta=-.077, \mathrm{P}>.05)$. Finally, ethical leadership is exerting a significant positive effects on employees' perceived meaningful work $(\beta=.815, \mathrm{P}<.05)$. Thus, we accept the $\mathrm{H} 1$ and $\mathrm{H} 3$ while rejected the $\mathrm{H} 2$.

R2 indicates the variance explained by the independent variables in the corresponding dependent variables. The $\mathrm{R} 2$ value in our study indicates that the independent variable explains $51.1 \%$ and $66.5 \%$ variation in the dependent variables of innovative work behavior and perceived meaningful work which can be considered satisfactory. The f-square (effect size) explains the predictive power of the predictors in a model. The f-square value of 0.02 is considered a small effect, 0.15 as medium effects, and 0.35 is considered as large effect sizes (Cohen, 1988; Roldán \& Sánchez-Franco, 2012). In our results, we can see that f2 is above 0.02 for all variables so it shows that the effect size is ranging between small to medium effect. Q2 is about predictive relevance of a particular model for its specific construct in the sample (Hair et al., 2017). The Q2 value of above 0 is considered as acceptable and shows a certain degree of predictive relevance. We used the Blindfolding procedure in SmartPLS to obtain Q2. The result shows that model has good predictive relevance as all Q2 are greater than the critical value of 0 .

Table 6

Specific Indirect Effects (Mediation Testing)

\begin{tabular}{ccccccc}
\hline H. No. & Paths & $\begin{array}{c}\text { Original } \\
\text { Sample (O) }\end{array}$ & $\begin{array}{c}\text { Sample Mean } \\
(\mathbf{M})\end{array}$ & $\begin{array}{c}\text { Standard } \\
\text { Deviation } \\
(\text { STDEV) }\end{array}$ & $\begin{array}{c}\text { T Statistics } \\
(|\mathbf{O S T D E V}|)\end{array}$ & $\begin{array}{c}\text { P- } \\
\text { Values }\end{array}$ \\
\hline H4 & EL>PMW>IWB & -.634 & -.869 & .891 & .711 & 477 \\
\hline
\end{tabular}

We tested the specific indirect effects for mediation/indirect effects hypotheses. The result indicates that the indirect effects of ethical leadership on employee innovative work behavior mediated by perceived meaningful work is negative and insignificant $(\beta=-.634, \mathrm{P}>.05)$ so we reject the H4. In other words, we could not find statistical support for the mediation hypothesis. 


\section{Discussion}

We aim to test a model based for explaining the innovative work behavior of employees predicted by ethical leadership and perceived meaningful work. The focus of the study was the ICT sector in the Sultanate of Oman. Our first major finding is that ethical leadership exert a significant positive influence on innovative work behavior of employees in ICT sector. Earlier studies including Duan et al., (2018); Feng et al., (2018); Shafique et al., (2019); and Javed et al., (2017) also support our finding. The second finding is that perceived meaningful work has insignificant effects on employee innovative work behavior suggesting that there is a need to search for better predictors explaining the innovative work behavior. These findings are inconsistent with the earlier findings including Soane et al., (2013); Liden et al., (2014); $\mathrm{Tu}$ and $\mathrm{Lu}$ (2013). The third major finding is that there is ethical leadership exert a significant positive influence on employees' perceived meaningful work. This finding is consistent with the findings of earlier studies including Wang and Xu (2019); and Mostafa and Abed ElMotalib (2020). Our fourth finding is that we did not find support for the mediating role of perceived meaningful work between the relationship of ethical leadership and employee innovative work behavior. These findings suggest that there will be other possible mediator and moderator which influence this relationship and thus requires empirical investigation in the future. Overall, our finding suggests that for employee's innovative work behavior, the leadership role is very important. In other words, ethical and developmental oriented leadership can contribute positively in shaping employee innovative work behavior in the ICT sector in this particular context.

\section{CONCLUSION}

Our findings show that ethical leadership influence positively the employee's innovative work behavior and perceived meaningful work. Our findings contribute to innovative work behavior and ethical leadership literature. We enrich the literature by empirically testing the ethical leadership and employee innovative work behavior relationship in this particular context of the ICT sector in Oman which also fills the literature gap.

\section{Recommendations}

- The ICT sector in Oman needs to focus on the leadership style of supervisors and team leaders who should be oriented about the adoption of the right leadership style to obtain favorable employee outcomes such as innovative work behavior.

- The ICT sector in Oman should hire such employees who possess the capacity to be future ethical leaders.

- While making promotion decisions related to the supervisory posts, ethical leadership should also be considered as a criterion.

- Suitable coaching and training should be arranged for the line managers and team leaders to develop an appropriate leadership style

\section{Limitations of the Study}

One limitation of the study is that we used a small sample from selected firms so generalization of the finding is difficult. Another limitation is that we used the adapted measure which may not be understood very well and may not have tapped the underlying concepts very well. The sole use of the quantitative approach and a single method of data collection is also a limitation of the study. 


\section{Directions for Future Research}

A future researcher should use the more diverse mediators and moderators and predictors to establish a true nature of the different leadership styles and influence on employee innovative work behavior. One avenue of future research can be the study of contextual factors that prohibit the employees to be involved in innovative work behavior.

\section{Acknowledgements}

The author want to thanks the management of the ICT firms and HR department for providing support in the process of data collection.

\section{Conflict of Interest Statement}

No conflict of interest has been declared by the different authors.

\section{References}

Abstein, A., \& Spieth, P. (2014). Innovative Work Behaviour: The impact of Comprehensive Hr System Perceptions and the role of Work-Life Conflict. Industry and Innovation, 21(2), 91-116. https://doi.org/10.1080/13662716.2014.896159

Akgunduz, Y., Alkan, C., \& Gök, Ö. A. (2018). Perceived organizational support, employee creativity and proactive personality: The mediating effect of meaning of work. Journal of Hospitality and Tourism Management, 34, 105-114. https://doi.org/10.1016/j.jhtm.2018.01.004

Amabile, T. M., \& Pratt, M. G. (2016). The dynamic componential model of creativity and innovation in organizations: Making progress, making meaning. Research in Organizational Behavior, 36, 157-183. https://doi.org/10.1016/j.riob.2016.10.001

Amabile, T. M., Conti, R., Coon, H., Lazenby, J., \& Herron, M. (1996). Assessing the work environment for creativity. Academy of Management Journal, 39(5), 1154-1184. https://doi.org/10.2307/256995

Avolio, B. J. (1999). Full leadership development: Building the vital forces in organizations. Thousand Oaks, CA: Sage.

Bartlett, J., Kotrlik, J.W., \& Higging, C.C. (2001). Organizational Research: Determining Appropriate Sample Size in Survey Research. Information Technology, Learning, and Performance Journal, 19(1). Retrieved from http://citeseerx.ist.psu.edu/viewdoc/download?doi=10.1.1.486.8295\&rep=rep1\&type= pdf

Bass, B. M. (1990). Bass and Stodgill's handbook of leadership. New York Free Press.

Brown, M. E., \& Treviño, L. K. (2006). Ethical leadership: A review and future directions. Leadership Quarterly, 17, 595-616. https://doi.org/10.1016/j.leaqua.2006.10.004

Browne, A. (2020). Lighting the Way: The case for ethical leadership in schools. Bloomsbury Publishing.

Cohen, J. (1988). Statistical Power Analysis for the Behavioral Sciences (2nd ed.), Lawrence Erlbaum, Hillsdale, NJ. 
De Jong, J., \& Den Hartog, D. (2010). Measuring innovative work behaviour. Creativity and Innovation Management, 19(1), 23-36. https://doi.org/10.1111/j.14678691.2010.00547.x

Duan, S., Liu, Z., \& Che, H. (2018). Mediating influences of ethical leadership on employee creativity. Social Behavior and Personality: An International Journal, 46(2), 323-337. https://doi.org/10.2224/sbp.6160

Feng, J., Zhang, Y., Liu, X., Zhang, L., \& Han, X. (2018). Just the right amount of ethics inspires creativity: A cross-level investigation of ethical leadership, intrinsic motivation, and employee creativity. Journal of Business Ethics, 153(3), 645-658. https://doi.org/10.1007/s10551-016-3297-1

Fornell, C., \& Larcker, D. F. (1981). Evaluating Structural Equation Models with Unobservable Variables and Measurement Error. Journal of Marketing Research, 18(1), 39-50. https://doi.org/10.2307/3151312

Grant, A. M., \& Berry, J. W. (2011). The necessity of others is the mother of invention: intrinsic and prosocial motivations, perspective taking, and creativity. Academy of Management Journal, 54, 73-96. https://doi.org/10.5465/AMJ.2009.43670890

Hair, J. F., Sarstedt, M., Ringle, C. M., \& Gudergan, S. P. (2017). Advanced issues in partial least squares structural equation modeling. Sage publications.

Huang, K. G. L., Geng, X., \& Wang, H. (2017). Institutional regime shift in intellectual property rights and innovation strategies of firms in China. Organization Science, 28, 355-377. https://doi.org/10.1287/orsc.2017.1117

Janssen, O. (2000). Job demands, perceptions of effort-reward fairness and innovative work behaviour. Journal of Occupational and Organizational Psychology, 73(3), 287-302.

Javed, B., Khan, A. A., Bashir, S., \& Arjoon, S. (2017). Impact of ethical leadership on creativity: the role of psychological empowerment. Current Issues in Tourism, 20(8), 839-851. https://doi.org/10.1080/13683500.2016.1188894

Jordan, J., Brown, M. E., Treviño, L. K., \& Finkelstein, S. (2013). Someone to look up to: Executive-follower ethical reasoning and perceptions of ethical leadership. Journal of Management, 39(3), 660-683. https://doi.org/10.1177/0149206311398136

Kalshoven, K., Den Hartog, D. N., \& De Hoogh, A. H. B. (2011). Ethical leadership at work questionnaire (ELW): Development and validation of a multidimensional measure. The Leadership Quarterly, 22(1), 51-69. https://doi.org/10.1016/j.leaqua.2010.12.007

Liden, R. C., Wayne, S. J., Liao, C., \& Meuser, J. D. (2014). Servant leadership and serving culture: Influence on individual and unit performance. Academy of Management Journal, 57(5), 1434-1452. https://doi.org/10.5465/amj.2013.0034

Ma, X., \& Jiang, W. (2018). Transformational leadership, transactional leadership, and employee creativity in entrepreneurial firms. The Journal of Applied Behavioral Science, 54(3), 302-324. https://doi.org/10.1177/0021886318764346

Martela, F., \& Pessi, A. B. (2018). Significant work is about self-realization and broader purpose: defining the key dimensions of meaningful work. Frontiers in Psychology, 9, 363. https://doi.org/10.3389/fpsyg.2018.00363

Moghimi, S., \& Subramaniam, I. D. (2013). Employees' creative behavior: The role of organizational climate in Malaysian SMEs. International Journal of Business and Management, 8(5), 1. https://doi.org/10.5539/ijbm.v8n5p1 
Mostafa, A. M. S., \& Abed El-Motalib, E. A. (2020). Ethical leadership, work meaningfulness, and work engagement in the public sector. Review of Public Personnel Administration, 40(1), 112-131. https://doi.org/10.1177/0734371X18790628

Oldham, G. R., \& Cummings, A. (1996). Employee creativity: Personal and contextual factors at work. Academy of Management Journal, 39(3), 607-634. https://doi.org/10.2307/256657

OmanObservers (2019). RO 100m investments to seed new ICT industry in Oman https://www.omanobserver.om/ro-100m-investments-to-seed-new-ict-industry/

Pradhan, S., \& Jena, L. K. (2019). Does meaningful work explains the relationship between transformational leadership and innovative work behaviour?. Vikalpa, 44(1), 30-40. https://doi.org/10.1177/0256090919832434

Pratt, M. G., \& Ashforth, B. E. (2003). Fostering meaningfulness in working and at work. Positive organizational scholarship: Foundations of a new discipline, 309, 327.

Pulapa, S. R. (2020). Need of the Hour: Ethical Leadership. In Business Ethics and The Bhagavad Gita (pp. 227-243). Springer, Cham.

Radwan, H. R. I. (2020). Leadership Styles in the Hotel Sector and Its Effect on Employees' Creativity and Organizational Commitment. International Journal of Social and Business Sciences, 14(3), 169-179.

Ringle, C. M., Wende, S., \& Becker, J. M. (2015). SmartPLS 3. SmartPLS GmbH. Bönningstedt, Germany. http://www.smartpls.com

Roldán, J. L., \& Sánchez-Franco, M. J. (2012). 'Variance-based structural equation modeling: Guidelines for using partial least squares in information systems research', In Research methodologies, innovations and philosophies in software systems engineering and information systems, IGI Global, pp.193-221.

Schaubroeck, J. M., Hannah, S. T., Avolio, B. J., Kozlowski, S. W., Lord, R. G., Treviño, L. K., \& Peng, A. C. (2012). Embedding ethical leadership within and across organization levels. Academy of Management Journal, 55(5), 1053-1078. https://doi.org/10.5465/amj.2011.0064

Shafique, I., Ahmad, B., \& Kalyar, M. N. (2019). How ethical leadership influences creativity and organizational innovation. European Journal of Innovation Management. https://doi.org/10.1108/EJIM-12-2018-0269

Simonton, D. K. (1999). Origins of Genius: Darwinian Perspectives on Creativity. Oxford: Oxford University Press.

Soane, E., Shantz, A., Alfes, K., Truss, C., Rees, C., \& Gatenby, M. (2013). The association of meaningfulness, well-being, and engagement with absenteeism: a moderated mediation model. Human Resource Management, 52, 441-456. https://doi.org/10.1002/hrm.21534

Steger, M. F., \& Dik, B. J. (2010). 11 Work as Meaning: Individual and Organizational Benefits of Engaging in Meaningful Work.

Steger, M. F., Dik, B. J., \& Duffy, R. D. (2012). Measuring meaningful work: the work and meaning inventory (WAMI). Journal of Career Assessment, 20, 322-337. https://doi.org/10.1177/1069072711436160 
Tsai, C. T., \& Tseng, W. W. (2010). A research agenda of transformational leadership and innovative behavior for the hospitality industry: An integrated multilevel model. In In Annual International Council on Hotels Restaurants and Institutional Education Conference (pp. 1-11).

Tu, Y., \& Lu, X. (2013). How ethical leadership influence employees' innovative work behavior: a perspective of intrinsic motivation. Journal of Business Ethics, 116, 441455. https://doi.org/10.1007/s10551-012-1455-7

Walumbwa, F. O., Luthans, F., Avey, J. B., \& Okey, A. (2011). Authentically leading groups: The mediating role of collective psychological capital and trust. Journal of Organizational Behavior, 32, 4-24.

Wang, Z., \& Xu, H. (2019). When and for whom ethical leadership is more effective in eliciting work meaningfulness and positive attitudes: The moderating roles of core self-evaluation and perceived organizational support. Journal of Business Ethics, 156(4), 919-940. https://doi.org/10.1007/s10551-017-3563-x

West, M. A., \& Farr, J. L. (1990). Innovation at work. In M. A. West \& J. L. Farr (Eds.). Innovation and creativity at work (pp. 03-13). New York: John Wiley and Sons.

Yukl, G. A. (2017). Kepemimpinan dalam Organisasi: Leadership in Organization.

Zahra, T. T., Ahmad, H. M., \& Waheed, A. (2017). Impact of Ethical Leadership on Innovative Work Behavior: Mediating Role of Self-Efficacy. Journal of Behavioural Sciences, 27(1). 